\title{
GYNECOLOGICAL LAPAROSCOPIC SURGERY: LEARNING CURVE
}

\author{
Zohra Khanum, ${ }^{1}$ Amna Khanum, ${ }^{2}$ Aman-ur-Rehman ${ }^{3}$
}

\begin{abstract}
A study was conducted to review the learning curve of gynecological laparoscopic surgery from January 2012 to December 2014. Total 310 cases were included in the study. These patients had pelvic surgery including hysterectomy either total laparoscopic hysterectomy or laparoscopic assisted vaginal hysterectomy and Adenexal surgery (cystectomy, oophorectomy or adhesionolysis). After preoperative evaluation counseling and consent procedures were performed. Data was collected regarding patients profile variables, indications for surgery, intraoperative findings, intraoperative time, post operative recovery findings, analgesia requirements and discharge time from the hospital. Regarding the intraoperative time, comparison was made for duration of surgery in the 2012 and at the end of study period 2014.
\end{abstract}

Results: Results of the study showed that there was no significant increase in complication either minor or

Khanum Z. ${ }^{1}$

Professor of Obstetrics \& Gynaecology

FJMU / Sir Ganga Ram Hospital, Lahore

Khanum A. ${ }^{2}$

Assistant Professor of Obstetrics \& Gynaecology

KEMU / Lady Aitchison Hospital, Lahore

Rehman A.U. ${ }^{3}$

Associate Professor of Histopathology

Sheikh Zayed Hospital, Lahore major related to urinary tract or bowel injury. Operative time was decreased with time. Most common indication for hysterectomy was fibroid uterus or dysfunctional uterine bleeding. Most common indication for adenexal pelvic surgery was ovarian cyst and in most cases cystectomy was done. Patient recovery was smooth and post operative analgesia was much less as compared to the routine. Patient hospital stay was less as compared to the routine procedures for hysterectomy.

It is concluded from the study that laparoscopic surgery is safe procedure with the clear advantages for the patient. With appropriate surgical training \& skills, the surgical time is reduced. In the study complication rate, operating time was comparable to the already published studies. With proper training it is acceptable alternate to open abdominal procedures with clear advantages for the patient.

Key words: Laparoscopic surgery, Learning curve.

\section{Introduction}

Modern endoscopy has changed the approach for the diagnostic as well as the operative procedures. In history of gynecological endoscopic surgery, there was great enthusiasm for laparoscopic surgery in the beginning but its growth was not as such what was expected. The major factor against its development is the learning curve of endoscopic surgery, its difficulty and the duration of surgery. As at most places the specialty is practiced as Obstetrics \& Gynecology, the workload of obstetrics is another bar for time. This time may be 
related to the surgical procedures or it may be related to the learning of the surgical procedures. This time and Obstetrical work burden becomes more important in professionals working in developing countries like Pakistan. Further more the fear of complication in unskilled hands is another barrier for the development of gynecological operative endoscopic surgery. This problem can be addressed by taking endoscopic surgery as a technique focusing on anatomy and ergonomics of the laparoscopic surgery. This will make learning simple, easier and the time issue and complications can be reduced.

It is established that Gynecological endoscopic surgery has clear advantages over the laparotomy. The advantages are in relation to lesser pain to patient, quicker recovery time. ${ }^{1,2}$ Patients need less analgesia in post operative time. Hospital stay is shorter. In addition to these there is very clear advantage for dealing with adnexal pathology. The pelvic anatomy and pathology is more clear under high magnification and surgeon is in better position to handle it.

Laparoscopic hysterectomy has clear advantage as compared to abdominal hysterectomy. ${ }^{3}$ Although vaginal hysterectomy is the less invasive method of hysterectomy and vaginal route for hysterectomy should be first route of choice for surgery. ${ }^{4,5}$ But vaginal hysterectomy has its technical limitations. It includes size of the uterus, pelvic adhesions, previous surgeries, vaginal access and surgeons expertise.

A study was conducted at Hameed Latif Hospital Lahore to see the Learning curve of the gynecological surgery by 310 cases over a period of three years.

\section{Materials and Methods}

In study 310 cases of laparoscopic surgery done for gynecological indications from January 2012 to December 2014 were included. These cases of laparoscopic surgery were done at Hameed Latif Hospital, Lahore. Data of all patients was reviewed in detail. It included age of patient, indication for surgery, in case of hysterectomy uterine size, additional pelvic pathology, previous pelvic surgeries, comorbidity, BMI of patient. The complications were divided in to early complications within 24 hours or delayed complication occurring after 24 hours. The surgical complications were defined according to evaluate study. ${ }^{5}$ The complications were defined as

\section{Major Complications:}

- Hemorrhage requiring reopen or blood transfusion.

- Hematoma requiring surgical drainage or blood transfusion.

- Urinary tract injury (ureter or urinary bladder).

- Bowel injury.

- Major anesthesia problem.

- Major anesthesia complication.

\section{Minor Complications:}

- Raised temperature >38 C on two occasions six hours apart excluding first 24 hours.

- Any sign of infection.

- Minor hematoma not requiring drainage.

- Minor anesthesia problems.

\section{Surgical Procedure}

After preoperative evaluation, counseling and consent surgery was planned. Additional counseling was done regarding the conversion of route of surgery (laparotomy) during the procedure. All patients received preoperative antibiotics cover. For procedure, in operation theatre under general anesthesia patient were placed in modified semi lithotomy position, with knees flexed. Urinary bladder was catherized. Vaginal manipulator was put in the uterus for its mobility (exceptions were unmarried girls). Intraumblical incision was given to create the pneumoperitoneum by veres needle. Intra abdominal pressure was maintained at $15 \mathrm{~mm} \mathrm{Hg}$. Ports were inserted. One central port of $10 \mathrm{~mm}$ was inserted intraumblical. Patient was put in Trendelenburg and other two side port of $5 \mathrm{~mm}$ on right lower quadrant were inserted. Pelvic anatomy was identified. The energy sources used were bipolar cautery, monopolar cautery and ligasure. Uterine anatomy along with adenexa was defined. The decision was made about the surgery. In case of hysterectomy following procedure was opted. The round ligament was dessicated with bipolar cautery and was cut. The infundopelvic ligament was desiccated. It was transected. The vesico uterine pouch was identified. It was incised by scissors and cautery. Uterus was manipulated by the manipulator. Vaginal fornices were identified. Incision was made in fornices. Uteroscaral ligament and cardinal ligaments were incised. Uterus was separated and was delivered through vagina. Vaginal cuff was closed by the vicryl No. 1.

In case of adnexal pathology, anatomy and pathology was identified. In the presence of adhesions, first 
adhesionolysis was done. In most of the cases cystictomy was done but in few cases oophorectomy was done. In cases of endometriosis additional fulguration of endometriotic spots was done. Hemostasis was checked. Operative time was noted for every case. Average blood loss was measured. Patients were given post operative care. Post operative analgesia was noted. They were discharged home after 24 hours to 48 hours after assessment and were followed after one week and four weeks follow-up.

\section{Results}

Total no of cases were 310 shown in table 1 . Indications for surgery for adenaxal pathology are shown in table 2 and Table 3 shows the indications for the hysterectomy.

Results of study showed that the age of the women ranged from 20 years to 65 years but most of the patients were between 30 to 48 years of age. The weight of patient ranged from $45 \mathrm{~kg}$ to $110 \mathrm{~kg}$. But most of the patients were between 60 to $70 \mathrm{Kg}$. Out of 310 patients, 70 patients had previous history of surgery (52 patients with previous LSCS and 3 previous history of myomectomy and 15 patients had history of laparotomy).

Regarding the operating time, it ranged from 80 minutes to 180 min with average time of about 100 minutes in most cases. The time duration of more than 100 minutes was noted in cases with previous surgery or larger size uterus. Uterine size ranged from 10 week size to 18 week size. The mean hospital stay excluding the preoperative period was $1.5 \pm 0.5$ day. Complication major or minor are shown in table 4 . One patient had urinary bladder trauma and it was recognized intra operatively and was managed at the same time. No patient had bowel injury or ureteric injury. Five patient had conversion to laparotomy, one because of adhesions and four patients because of size of uterus. Regarding the major complications only one patient had post operative hematoma requiring drainage. Among the

Table 1: Total cases: 310 .

\begin{tabular}{|l|r|}
\hline \multicolumn{1}{|c|}{ Cases } & No \\
\hline Laparoscopic Hysterectomy & 120 \\
\hline Adenaxal pathology & 170 \\
\hline Myomectomy & 20 \\
\hline
\end{tabular}

minor complications, the most common was related to urinary system. Vaginal vault spotting was noted in 15 patient which was settled in 2 to 3 days by conservative treatment.

Table 2: Lap Surgery for Adenexal Pathology: 170.

\begin{tabular}{|c|c|}
\hline \multicolumn{1}{|c|}{ Diagnosis } & No \\
\hline Ovarian pathology & \\
- Endometriosis & 51 \\
- Cyst & 37 \\
- Dermoid & 20 \\
Ectopic pregnancy & 12 \\
\hline Adhesionolysis & 35 \\
\hline
\end{tabular}

Table 3: Indications for Laparoscopic Hysterectomy.

\begin{tabular}{|l|l|}
\hline \multicolumn{1}{|c|}{ Indications } & No \\
\hline Fibroids & 32 \\
\hline Adenomyosis & 30 \\
\hline Endometrial hyperplasia & 22 \\
\hline Dysfunctional uterine bleeding & 21 \\
\hline Chronic pelvic pain & 05 \\
\hline Adenexal pathology & 05 \\
\hline Recurrent post menopausal bleeding & 04 \\
\hline CIN & 01 \\
\hline
\end{tabular}

Table 4: Operative complications.

\begin{tabular}{|c|c|}
\hline \multicolumn{1}{|c|}{ Complications } & No \\
\hline Major complications & \\
- Hemorrhage & 03 \\
- Hematoma & 02 \\
- Conversion to Laparotomy & 05 \\
- Injury to Urinary bladder & 01 \\
\hline Minor complications & \\
- Minor hemorrhage & 04 \\
- Urinary infections & 10 \\
- Vaginal vault spotting & 15 \\
\hline
\end{tabular}




\section{Discussion}

Minimal invasive surgery has very clear benefits to the patient. It has emerged as the therapeutic options in many procedures. For management of adenexal masses it the gold standard option. The safety of gynecological surgery can be improved by many factors. Proper step wise strategically learning can accelerate the learning as well as improve the learning curve in addition to the patients safety. The study shows the results of 310 cases done laparoscopically. The data of the study related to socio demographics, indications for surgery, patient body weight, indications for hysterectomy are same as mentioned already in previous studies. ${ }^{3,8,9}$ During learning period, experience of the surgeon is very important factor to affect the learning curve.

A study conducted in 1994 has shown that risk of Laparoscopic hysterectomy are the same as the abdominal hysterectomy and vaginal hysterectomy in skilled hands. ${ }^{10}$ It is similar to one other study that had showed the safety of laparoscopic hysterectomy equal to abdominal hysterectomy. ${ }^{11}$ In our study the results related to the complications are comparable to these already published studies. But one study shows that there is small increased risk of complication rate with laparoscopic hysterectomy. ${ }^{12-14}$ There was no increase in complication due to laparoscopic route for hysterectomy in our study. Another study has shown that after thirty hysterectomies done laparoscopically the rate of complications is equivalent to that using the other approaches. With expertise the average duration of hysterectomy is comparable with the other routes for hysterectomy. TLH has less duration of stay in hospital as compared to the LAVH especially in obese patients. ${ }^{15}$ But in our study it was found that the duration of surgery was longer in initial cases and duration of surgery was decreased with the expertise and knowing the technique. The incidence of conversion of the laparoscopic procedure to abdominal procedure (laparotomy) is different in different studies. In one study it is very low $0.6 \% .^{9,10}$ But in our study it was $5 \%$. Regarding the analgesia requirement, early recovery and back to work, shorter hospital stay the results of our study are comparable to already published study. ${ }^{3}$

\section{Conclusion}

The trend of gynecological laparoscopic surgery can be increased by improving the learning curve keeping the patients safety as the priority.

\section{References}

1. Olsson JH, Ellstrom M, Hahlin M. A randomized prospective trial comparing laparoscopic and abdominal hysterectomy. Br J Obstet Gynaecol 1996; 103: 34550.

2. Cheung VYT, Rosenthal DM. Laparoscopic versus abdominal supracervical hysterectomy. J Am Assoc Gynecol Laparosc. 2002; 9 (Suppl): S68.

3. Garry R, Fountain J, Mason S, Napp V, Brown J, Hawe $\mathrm{J}$, et al. The eVALuate study: two parallel randomized trials, one comparing laparoscopic with abdominal hysterectomy, the other comparing laparoscopic with vaginal hysterectomy. BMJ, 2004; 328: 129-36.

4. Lefebvre G, Allaire C, Jeffrey J, Vilos G. SOGC Clinical Practice Guidelines No. 109. Hysterectomy. J Obstet Gynaecol Can. 2002; 24: 37-48.

5. Garry R. The future of hysterectomy. BJOG, 2005; 112: 133-9.

6. Cheung VYT, Rosenthal DM. TLH versus LAVH. J Am Assoc Gynecol Laparosc. 2002; 9 (Suppl): S8.

7. Seracchioli R, Venturoli S, Vianello F, Govoni F, Cantarelli M, Gualerzi B. Total laparoscopic hysterectomy compared with abdominal hysterectomy in the presence of a large uterus. J Am Assoc Gynecol Laparosc. 2002; 9: 333-8.

8. Mueller A, Oppelt P, Ackermann S, Binder H, Beckmann MW. The Hohl instrument for optimizing total laparoscopic hysterectomy procedures. J Minim Invasive Gynecol. 2005; 12: 432-5.

9. Liu C, Reich H. Complications of total laparoscopic hysterectomy in 518 cases. Gynaecol Endosc. 1994; 3 : 203-8.

10. Liu C, Reich H. Complications of total laparoscopic hysterectomy in 518 cases. Gynaecol Endosc. 1994; 3: 203-8.

11. Ribeiro SC, Ribeiro RM, Santos NC, Pinotti JA. A randomized study of total abdominal, vaginal and laparoscopic hysterectomy. Int J Gynaecol Obstet. 2003; 83: 37-43.

12. Maresh MJA, Metcalfe MA, McPherson K, Overton C, Hall V, Hargreaves J, et al. The VALUE national hysterectomy study: description of the patients and their surgery. BJOG. 2002; 109: 302-12.

13. Makinen J, Johansson J, Tomas C, Tomas E, Heinonen PK, Laatikainen T, et al. Morbidity of 10110 hysterectomies by type of approach. Hum Reprod. 2001; 16: 1473-8.

14. Johnson N, Barlow D, Lethaby A, Tavender E, Curr L, Garry R. Methods of hysterectomy: systematic review and meta-analysis of randomised controlled trials. BMJ, 2005; 330: 1478.

15. Ghezzi F, Cromi A, Bergamini V, Uccella S, Beretta P, Franchi M, et al. Laparoscopic-assisted vaginal hysterectomy versus total laparoscopic hysterectomy for the management of endometrial cancer: a randomized clinical trial. J Minim Invasive Gynecol 2006; 13: 114-20. 